\title{
Robotic pulmonary segmentectomy
}

\author{
Kelsey A. Musgrove ${ }^{1}$, Charlotte R. Spear ${ }^{1}$, Kamil Abbas ${ }^{1}$, Britney R. Harris ${ }^{1}$, Ghulam Abbas ${ }^{2}$ \\ ${ }^{1}$ Department of General Surgery, West Virginia University, Morgantown, WV, USA; ${ }^{2}$ Department of Cardiovascular and Thoracic Surgery, West \\ Virginia University, Morgantown, WV, USA \\ Correspondence to: Ghulam Abbas, MD, MHCM, FACS. Chief, Division of Thoracic Surgery, 1 Medical Center Drive, Morgantown, WV 26508, \\ USA. Email: ghulam.abbas@hsc.wvu.edu.
}

Submitted Dec 09, 2019. Accepted for publication Dec 23, 2019.

doi: $10.21037 /$ jtd.2019.12.68

View this article at: http://dx.doi.org/10.21037/jtd.2019.12.68

\section{Introduction}

Lung cancer is responsible for approximately 154,000 deaths in 2018 and an estimated 142,000 deaths in 2019 making it the leading cause of cancer related mortality in the United States $(1,2)$. Among these, approximately only one-third of patients present with early stage disease that is amenable to surgical excision, this number increasing secondary to increased lung cancer screening (3).

Pulmonary segmental resection offers a lung preserving alternative technique especially critical for patients with emphysema. This technique was first introduced in 1939 by Churchill and Belsey for the treatment of bronchiectasis (4). Despite this early introduction, pulmonary lobectomy continued to be the standard of care for stage I and II lung cancer and was further validated in 1995 by Ginsberg et al. who reported concerning results of increased local recurrence rates and a $30 \%$ increase in mortality with segmentectomy $(5,6)$.

Since then, multiple studies have demonstrated equivalent outcomes for segmental resection without compromise in survival or recurrence when compared to lobectomy. One prospective, randomized, multi-institutional trial conducted by the Cancer and Lymphoma Group B included 697 patients from 2007 to 2013 with T1N0 peripheral tumors smaller than $2 \mathrm{~cm}$ and non-small cell pathology. Early results have been promising, with similar outcomes for patients randomized to lobectomy versus segmentectomy (7). In addition, multiple retrospective studies have shown equivalent disease-free survival and similar recurrence rates (8-18). Okada et al. also noted that the extent of removed lung parenchyma directly affected postoperative functional loss even at 6 months after surgery and segmentectomy offered significantly better functional preservation (15). This data has allowed segmentectomy to become a reasonable alternative, with no compromise to oncologic survival and the advantage of sparing more viable parenchyma compared to standard lobectomy.

Anatomical pulmonary segmentectomy requires meticulous intraparenchymal dissection to expose the segmental bronchus and vessels. Open technique was gradually replaced by more minimally invasive techniques, with video-assisted thoracoscopic (VATS) seen to have comparatively excellent results in morbidity, rates of locoregional recurrence, and cancer-free survival compared to standard open technique (19-23). Robotic-assisted techniques were introduced at the end of the 1990s, the first series published for robotic lobectomy in 2002 (24). Few prior studies have examined robotic segmentectomy, the first a multicentric study reporting on 17 patients from 2008 to 2010 followed by Toker et al. in 2014 reporting on 21 patients (25-27). These early studies have concluded that robot-assisted thoracoscopic segmentectomy is safe and associated with few complications, short hospitalization, and oncologically acceptable lymph node harvest. However, no prospective studies have been performed comparing robotassisted to video-assisted thoracoscopic segmentectomy.

Musgrove et al. compared their early robotic segmentectomy experience with VATS segmentectomy in their single institution retrospective analysis (28). The median length of stay was 2 days with robotic approach as compared to 4 days with VATS and although patients in the robotic group had inferior pulmonary function, they had fewer post-operative complications. Additionally, Liang et al. performed a meta-analysis comparing outcomes of robotic lobectomy and segmentectomy with videoassisted lobectomy and segmentectomy. They showed 
Table 1 Robotic pulmonary segmentectomies

Right upper lobe segments

1. Right upper lobe apical segment $s_{1}$

2. Right upper lobe posterior segment $\mathrm{s}_{2}$

3. Right upper lobe anterior segment $\mathrm{s}_{3}$

4. Right upper lobe apico-posterior segmentectomy $S_{1}+S_{2}$

Left upper lobe segments

1. Left upper lobe upper division segmentectomy $S_{1}+S_{2}+S_{3}$

2. Left upper lobe apico-posterior segmentectomy $S_{1}+S_{2}$

3. Left upper lobe lingular segmentectomy $S_{4}+S_{5}$

fewer conversions to open and increased completion of the planned segmentectomy with robotic approach (29). Overall, the few experiences described in the literature confirm robotic-assisted thoracoscopic surgery is a safe alternative to VATS and an increasing number of surgeons are finding it an easier approach with the potential advantages of better visualization with three-dimensional optics, increased precision from articulating instruments providing seven degrees of motion, enhanced dexterity, and tremor filtration $(27,30)$.

\section{Pre-operative planning for robotic segmentectomy}

The knowledge of the anatomy of the pulmonary segments is essential. The surgeon should be able to imagine the $3 \mathrm{D}$ anatomy of the segment of the interest. Pre-operative CT chest with $3 \mathrm{D}$ reconstruction can be extremely helpful to become familiar with the segmental anatomy and identify the branches of the vein, pulmonary artery, and bronchus to the particular segment. This also allows the surgeon to decide if segmentectomy would be an adequate oncological resection $(31,32)$.

Pre-operative localization of the smaller deeper nodule can be helpful for intra-operative identification of the lesion. Multiple reports of using navigation bronchoscopy to localize smaller deeper lung nodules have been published (33-35).

\section{Techniques of robotic pulmonary segmentectomies}

The commonly performed robotic upper lobe segmentectomies are listed in Table 1.
Table 2 Robotic ports and instruments for robotic pulmonary segmentectomies

Robotic ports

- Two $8 \mathrm{~mm}$ robotic ports for camera and para-spinal port

- Two $12 \mathrm{~mm}$ robotic ports, one anterior to the camera port and the other posterior

Robotic instruments

- Curve tip bipolar dissector

- Cadiere forcep

- Tip up fenestrated lung grasper

Locations of instruments (right)

- Arm 1: Curve tip bipolar dissector

- Arm 2: Camera

- Arm 3: Cadiere Forcep

- Arm 4: Tip up lung grasper

Locations of instruments (left)

- Arm 1: Tip Up Lung Grasper

- Arm 2: Curve Tip Bipolar Dissector

- Arm 3: Camera

- Arm 4: Cadiere Forcep

The robotic segmentectomies are performed at the authors' institution using Da Vinci (Intuitive, Sunnyvale CA) Si and Xi Platforms. Robotic staples are preferentially used when using Xi system while Ethicon (Johnson \& Johnson, Cincinnati $\mathrm{OH}$ ) endocutter and PVS vascular motorized stapler are used with Si system. The standard 4-arm robotic technique for anatomical lung resection is used. The robotic ports and instruments are listed in Table 2.

\section{Steps of the procedure}

\section{Port placement for robotic segmentectomy}

Figures 1 and 2 show the usual port placement for the left and right sided upper lobe segmentectomy. The tip of the 11th rib is identified. The $5 \mathrm{~mm}$ laparoscopic port is placed in either the 7 th or 8 th intercostal space in the posterior axillary line, depending on the planned segmentectomy. The posterior port is placed $10 \mathrm{~cm}$ posterior to the camera port. The paraspinal port is placed $4 \mathrm{~cm}$ lateral to the spine. The anterior port is placed $10 \mathrm{~cm}$ anterior to the camera port, but one or two intercostal spaces superior to the rest of the 


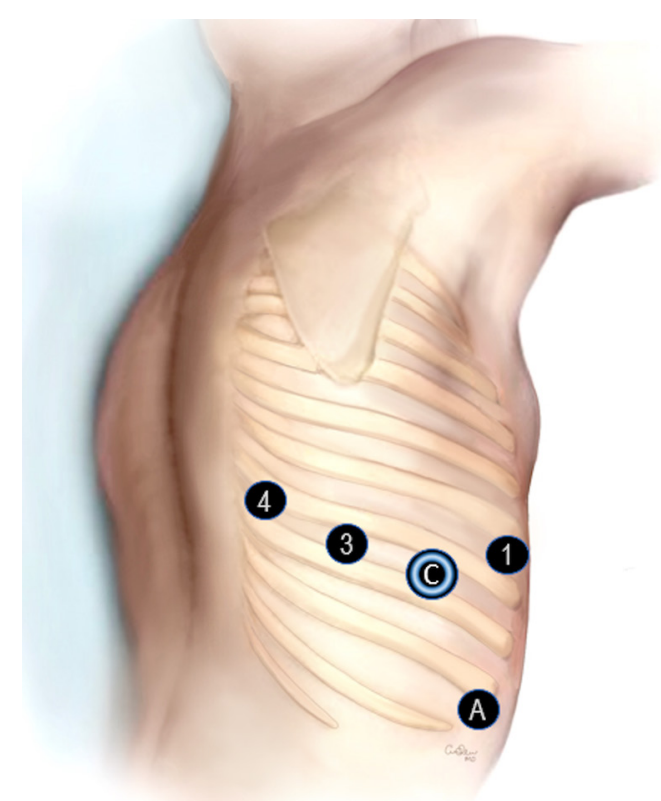

Figure 1 Right sided port placement. Arms 1-4. C is camera port at Arm 2. A is assistant port.

ports. The assistant port is placed under direct vision just above the diaphragm between the camera and the anterior ports. This port is placed after $\mathrm{CO}_{2}$ insufflation is started to avoid diaphragmatic injury. The robot is docked. At this point the $5 \mathrm{~mm}$ camera port is switched to robotic camera port. The standard mediastinal lymph node dissection is performed.

\section{Right upper lobe apical segmentectomy $\left(S_{1}\right)$}

After completion of the mediastinal lymph node dissection, the lung is retracted anteriorly using the fourth arm. The pleura over the posterior surface of lung is opened and the bronchus is exposed. The bronchus intermedius and upper lobe are visualized, and the latter is dissected. The lymph node between the right upper lobe bronchus and bronchus intermedius is removed. The lung parenchyma is dissected off the bronchus using the bipolar dissector.

Subsequently the pleura over the apex and hilum is opened. The soft tissue/lymph node between the apical vein and the first branch of the pulmonary artery is removed. The first branch of the pulmonary artery is skeletonized. The division of the artery into the anterior segmental branch (A3) and one to two apical segmental (A1) branches are identified and dissected (Figure 3A). Subsequently the upper lobe vein is dissected and its division into the central

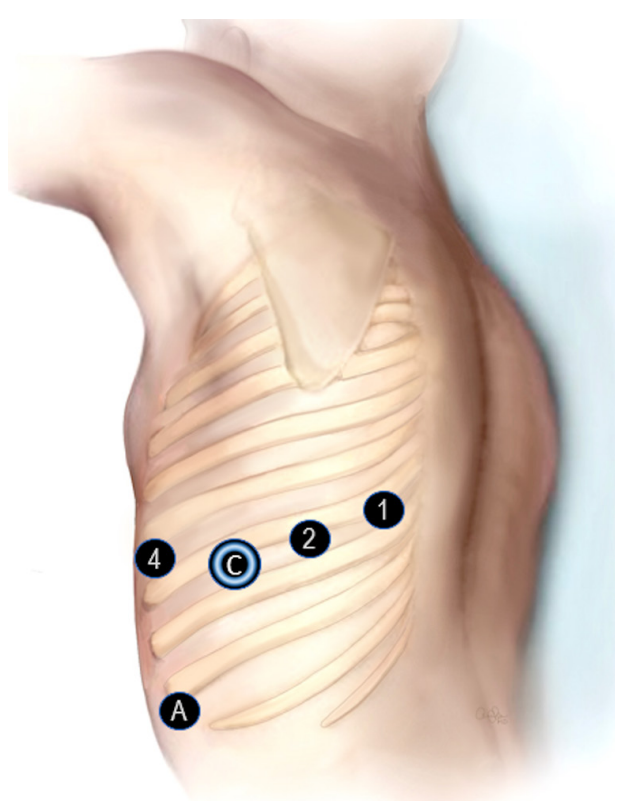

Figure 2 Left sided port placement. Arms 1-4. C is camera port at Arm 3. A is assistant port.

vein and apical vein is identified (Figure 3B). The apical segmental vein (V1) is isolated and transected with the stapler introduced through the arm 3. Subsequently the apical segmental artery (A1) is isolated and transected with the stapler introduced through arm 1 . This allows exposure to the bronchus. With the lung retracted, the apical segmental bronchus (B1) is the first branch encountered (Figure 3C). The bronchus is carefully dissected and encircled using a vessel loop. The stapler is passed through the arm 1. The bronchus is transected. Subsequently the Parenchyma of the segment is transected by stapler introduced through arm 1.

\section{Right upper lobe posterior segmentectomy $\left(S_{2}\right)$}

After completion of the mediastinal lymph node dissection, the lung is retracted anteriorly using the fourth arm. The pleura over the posterior surface of lung is opened. The bronchus is exposed. The bronchus intermedius and upper lobe bronchus are visualized, and the latter is dissected. The lymph node between the right upper lobe bronchus and bronchus intermedius is removed. The lung parenchyma is dissected off the bronchus using the bipolar dissector. The pleura over the apex of the lung is opened.

The dissection is performed in the major fissure to identify the pulmonary artery. Subsequently, the fissure is 

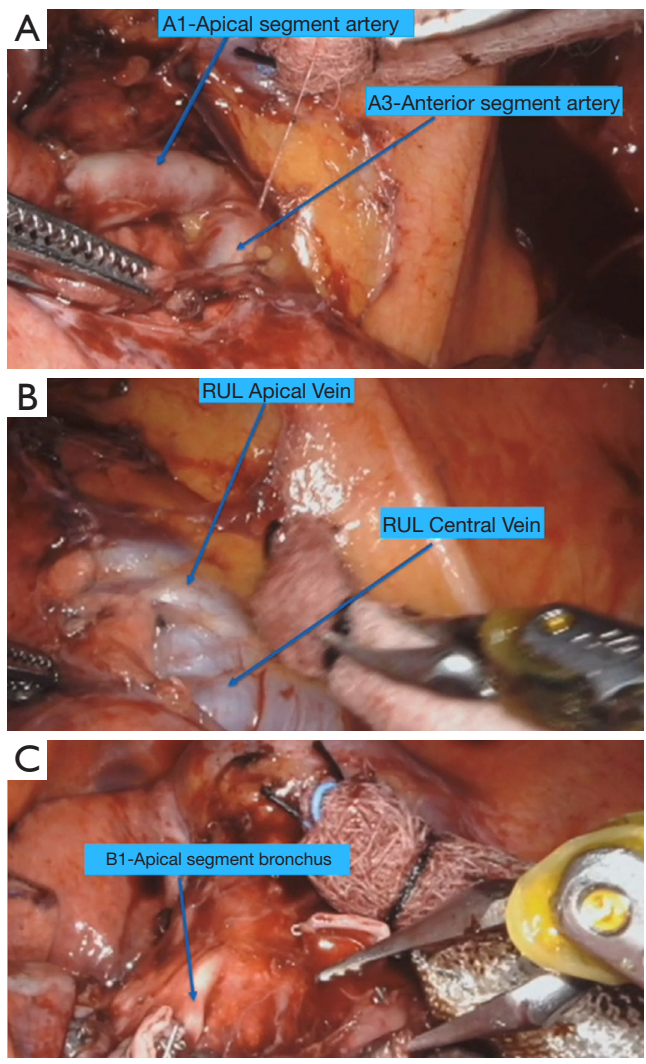

Figure 3 Right upper lobe apical segmentectomy (S1). (A) View of the first branch of right pulmonary artery dividing into anterior (A3) and apical branches (A1) with lung retracted caudally. (B) Right upper lobe vein with lung retracted posteriorly. (C) Right upper lobe apical segment bronchus (B1) after the transection of A1.

completed by introducing the stapler through arm 1 . The posterior segmental artery (A2) and vein (V2) are identified (Figure 4A). They are dissected and isolated. Both can be transected using a single stapler fire introduced through arm 1. This leads to the exposure of the posterior segmental bronchus (B2) (Figure 4B). With the lung retracted toward the lateral chest wall, the $\mathrm{B} 2$ is easily identified. The bronchus is dissected carefully and transected with stapler introduced through arm 1 . Subsequently the parenchyma is transected by introducing the stapler through arm 1 .

\section{Right upper lobe apico-posterior segmentectomy $\left(S_{1}+S_{2}\right)$}

The technique of apico-posterior segmentectomy is combination of S1 and S2 Segmentectomy. The pleura over the posterior surface and apical surface is opened as usual. The fissure is completed posteriorly and A2 and V2

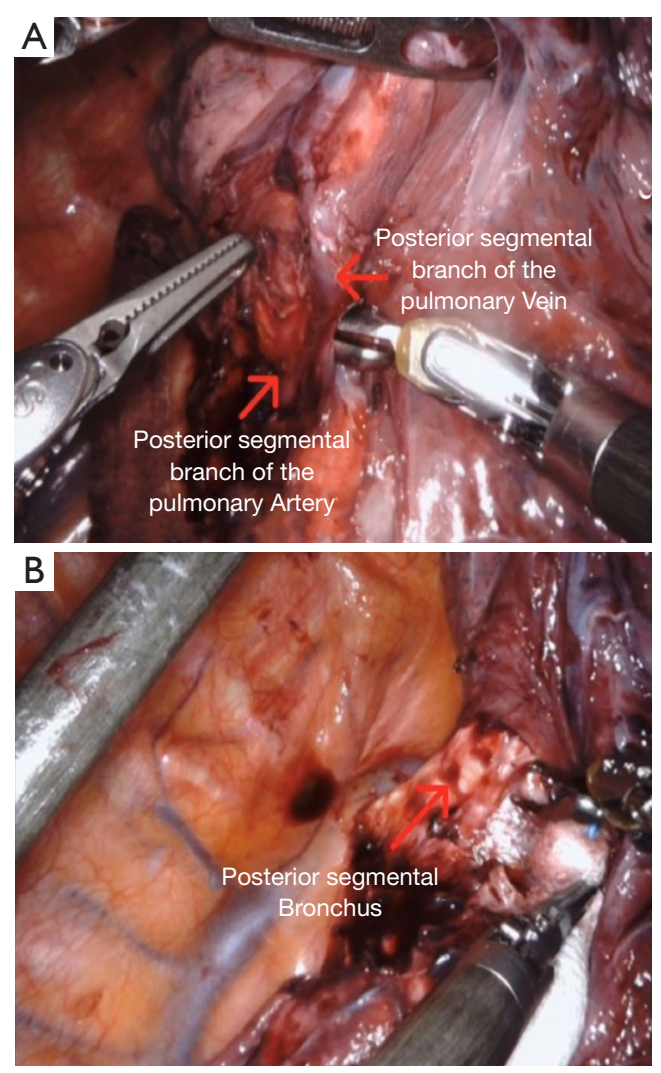

Figure 4 Right upper lobe posterior segmentectomy (S2). (A) Right upper lobe posterior segmental artery (A2) and Vein (V2). (B) Right upper lobe posterior segment bronchus (B2) after the transection of artery and vein.

are transected as done in S2 segmentectomy. Subsequently the $\mathrm{V} 1$ and $\mathrm{A} 1$ are transected as done in $\mathrm{S} 1$ segmentectomy. The bronchi B2 and B1 are usually taken in once sparing the $\mathrm{B} 3$ from the fissure approach.

\section{Right upper lobe anterior segmentectomy $\left(S_{3}\right)$}

After the completion of the mediastinal lymph node dissection, the pleura over the apex of the lung is opened and the anterior segmental artery (A3) is dissected. The apical vein (V1) is isolated and retracted for the exposure. The upper lobe vein is dissected in preparation to complete the fissure anteriorly.

The dissection is done in the fissure to expose the central vein (Figure 5A). The posterior segmental vein (V2) is preserved. The anterior segmental vein (V3) is isolated and transected which leads to the exposure of the truncus 

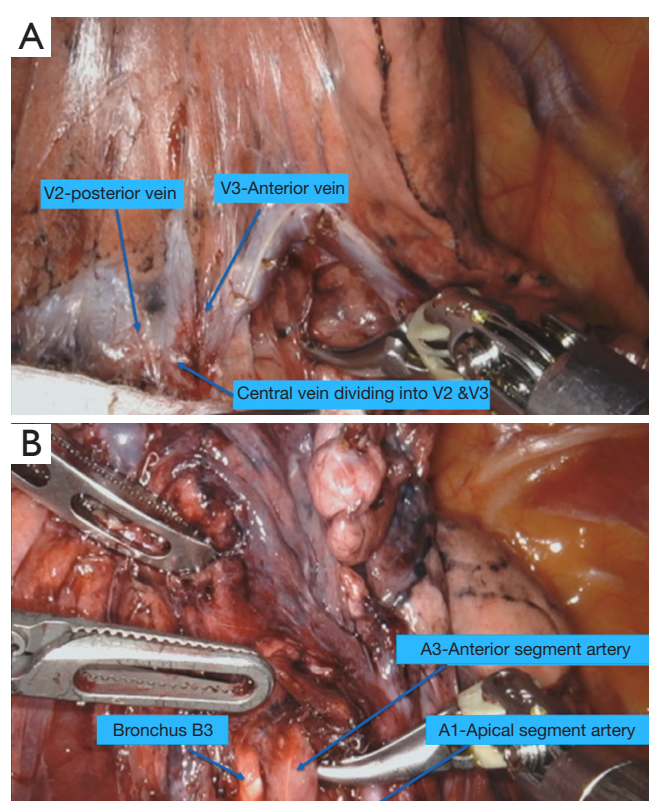

Figure 5 Right upper lobe anterior segmentectomy (S3). (A) Right upper lobe central vein division into posterior segmental (V2) and anterior segmental vein (V3). (B) Exposure of anterior segmental artery (A3) and bronchus (B3) after the division of the vein (V3).
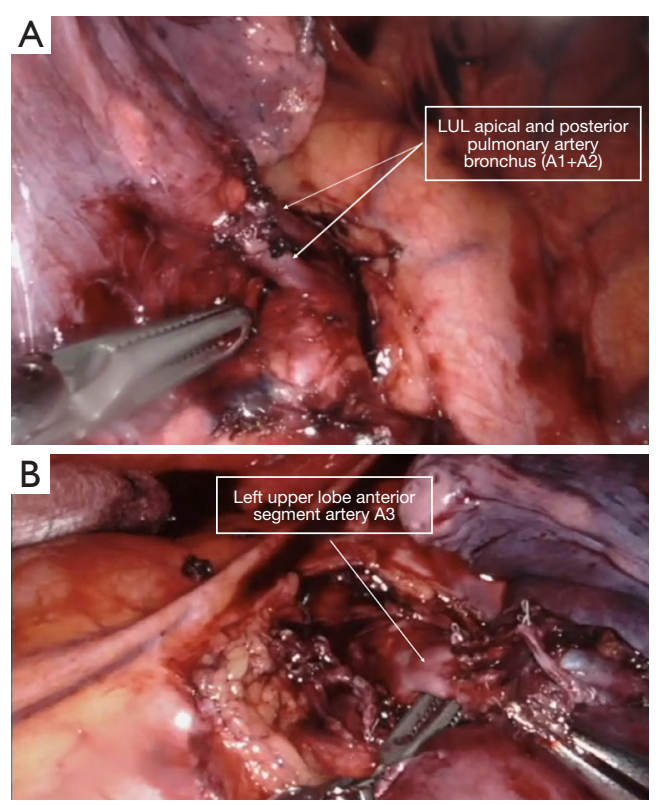

Figure 6 Left upper lobe upper division segmentectomy $(\mathrm{S} 1+\mathrm{S} 2+\mathrm{S} 3)$. (A) Left upper lobe apical and posterior segmental arteries. (B) Left upper lobe anterior segmental artery (A3) after the division of upper lobe upper division vein.

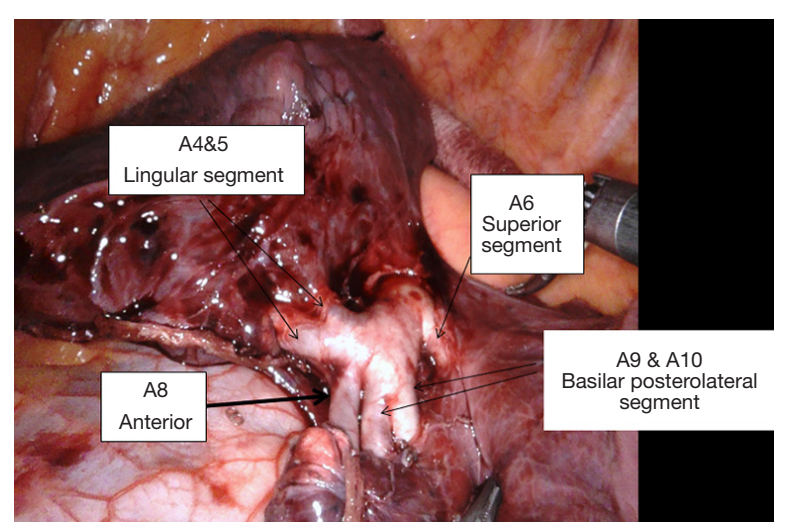

Figure 7 Left pulmonary artery in the fissure with exposure of lingular and lower lobe branches.

branch of the pulmonary artery. The fissure is completed anteriorly. The anterior segmental artery (A3) is dissected and transected. The bronchus (B3) is dissected and transected (Figure $5 B$ ). Finally, the parenchyma is resected by introducing the stapler from the posterior port.

\section{Left upper lobe upper division segmentectomy $\left(S_{1}+S_{2}+S_{3}\right)$}

This procedure is also known as trisegmentectomy, Lingular sparing segmentectomy or Culmen resection. After completion of the mediastinal lymph node dissection, the lung is retracted anteriorly using the fourth arm. The pleura over the posterior surface of lung is opened exposing the pulmonary artery posteriorly. The soft tissue over the artery is dissected and dissection is carried into the posterior part of the fissure. The fissure is completed posteriorly exposing the posterior segmental arteries. There usually are two branches $(\mathrm{A} 1+\mathrm{A} 2)$ which are dissected and transected (Figure $6 \mathrm{~A}$ ). The lung is retracted posteriorly and the upper lobe vein is dissected, exposing the upper division and lingular branches. The upper division vein is transected allowing exposure of the first branch of the pulmonary artery (A3). The branch is dissected and transected. Generally, one or more lymph nodes are found at this location as well as between the lingular and apical bronchi. They are dissected and sent for frozen section. The left upper lobe bronchus is dissected and its division into upper division and lingular branches 
is identified. The upper division bronchus is transected. Subsequently the parenchyma is transected.

\section{Left upper lobe apicoposterior segmentectomy $\left(S_{1}+S_{2}\right)$}

Similar to the upper division segmentectomy, the dissection into the fissure posteriorly is performed to expose and transect the posterior segmental arteries. Subsequently the apical branch (A1), which may be arising as a common trunk with $\mathrm{A} 3$, is isolated and transected (Figure 6B). The upper division bronchus is dissected to expose its division into anterior (B3) and apico-posterior bronchi $(\mathrm{B} 1+\mathrm{B} 2)$. The bronchus is transected and subsequently the parenchyma is resected in the line of the bronchial stump using the stapler.

\section{Lingular segmentectomy $\left(S_{4}+S_{5}\right)$}

After completion of the mediastinal and interlobar lymph node dissection, the lung is retracted anteriorly using the fourth arm. The pleura over the posterior surface of lung is opened. Subsequently the fissure is exposed. The pulmonary artery is dissected in the fissure and the lingular, basilar, and superior segmental branches are identified (Figure 7). The lingular branches (A4+A5) of the pulmonary artery are transected. The lingular vein is subsequently transected. The fissure is completed anteriorly. This allows exposure to the lingular bronchus, which is usually transected with blue load stapler. The Parenchyma is subsequently transected.

\section{Superior segmentectomy $\left(S_{6}\right)$}

The steps of superior segmentectomy are almost similar on both sides. The dissection is started by incising the inferior pulmonary ligament, exposing the inferior pulmonary vein posteriorly. The superior segment vein is angled superiorly and can easily be isolated from basilar segment branch. Subsequently the dissection is performed in the fissure to expose the pulmonary artery superior segment A6 and basilar segment arterial branches. The fissure is completed posteriorly. The A6 is isolated and transected. Subsequently the venous branch V6 is transected. The bronchus B6 is dissected in the fissure, isolated and transected. The parenchyma is resected in the line of the bronchial stump.

\section{Lower lobe antero-medial segmentectomy $\left(S_{7}+S_{8}\right)\left(S_{7}\right.$ is absent on left)}

The segment $\mathrm{S} 7$ is missing on the left side. On the right the dissection is done in the fissure to expose the most medial branch of the basilar segment artery A7 and it is followed cephalad to identify the anterior segment branch A8. These two branches usually come off as a common trunk from the basilar segmental artery. On the left only A8 is encountered. The fissure is completed anteriorly on the left and between middle and lower lobe on the right. The arterial branches are transected. This exposes the superior basilar vein usually draining S7 and S8. This is transected leading to good exposure of the bronchus which is also either transected or cut and oversewed.

\section{Lower lobe postero-lateral segmentectomy $\left(S_{9}+S_{10}\right)$}

The inferior pulmonary ligament is incised and the vein is dissected. Next, the dissection is performed in the fissure to expose the basilar segmental artery and its division into antero-medial and postero-lateral (A9+A10) branches. The latter is isolated and transected, exposing the bronchus $(\mathrm{B} 9+\mathrm{B} 10)$. The bronchus is transected which leads to exposure of the veins V9 \& V10. The veins are transected.

\section{Conclusions}

Pulmonary segmentectomy using the robotic platform is a safe approach. The robotic platform allows for meticulous dissection enabling the surgeons to resect almost all pulmonary segments via minimally invasive approach with less conversion to open and shorter length of stay comparing to VATS.

\section{Acknowledgments}

We acknowledge West Virginia University. Funding: None.

\section{Footnote}

Provenance and Peer Review: This article was commissioned by the editorial office, Fournal of Thoracic Disease for the series "Robotic Thoracic Surgery". The article has undergone external peer review.

Conflicts of Interest: All authors have completed the ICMJE uniform disclosure form (available at http:// dx.doi.org/10.21037/jtd.2019.12.68). The series "Robotic Thoracic Surgery" was commissioned by the editorial office without any funding or sponsorship. Ghulam Abbas served 
as the Guest Editor of the series and serves as an unpaid editorial board member of fournal of Thoracic Disease. The authors have no other conflicts of interest to declare.

Ethical Statement: The authors are accountable for all aspects of the work in ensuring that questions related to the accuracy or integrity of any part of the work are appropriately investigated and resolved. Written informed consent was obtained from the patient for publication of this manuscript and any accompanying images.

Open Access Statement: This is an Open Access article distributed in accordance with the Creative Commons Attribution-NonCommercial-NoDerivs 4.0 International License (CC BY-NC-ND 4.0), which permits the noncommercial replication and distribution of the article with the strict proviso that no changes or edits are made and the original work is properly cited (including links to both the formal publication through the relevant DOI and the license). See: https://creativecommons.org/licenses/by-nc-nd/4.0/.

\section{References}

1. Siegel R, Naishadham D, Jemal A. Cancer statistics. CA Cancer J Clin 2012;62:10-29.

2. National Cancer Institute: Surveillance, Epidemiology, and End Results Program. Reports on Cancer. [Internet]. April 2018. Available online: https://seer.cancer.gov/statfacts/ $\mathrm{html} / /$ common.html.

3. De Koning H, Van Der Aalst C, Ten Haaf K, et al. Effects of volume CT lung cancer screening: mortality results of the Nelson randomised-controlled population based trial. Sept 2019. Presented at IASLC: 20th World Conference on Lung Cancer. Barcelona, Spain.

4. Churchill ED, Belsey R. Segmental Pneumonectomy in Bronchiectasis: The lingula segment of the upper lobe. Ann Surg 1939;109:481-99.

5. Crinò L, Weder W, van Meerbeeck J, et al. Early stage and locally advanced (non-metastatic) non-small-cell lung cancer: ESMO Clinical Practice Guidelines for diagnosis, treatment and follow-up. Ann Oncol 2010;21 Suppl 5:v103-15.

6. Ginsberg RJ, Rubenstein LV. Randomized trial of lobectomy vs limited resection for T1 N0 Non-small cell lung cancer. Ann Thorac Surg 1995;60:615-22; discussion 622-3.

7. Mitchell, KG, Antonoff MB. Encouraging early outcomes in cancer and leukemia group B (CALGB)/Alliance
140503: patient selection, not extent of resection, is the key to perioperative success. Ann Transl Med 2019;7:S50.

8. Jensik RJ, Faber LP, Kittle CF, et al. Survival following resection for second primary bronchogenic carcinoma. J Thorac Cardiovasc Surg 1981;82:658-68.

9. Cao C, Chandrakumar D, Gupta S, et al. Could less be more?-A systematic review and meta-analysis of sublobar resections versus lobectomy for non-small cell lung cancer according to patient selection. Lung Cancer 2015;89:121-32.

10. Yang F, Sui X, Chen X, et al. Sublobar resection versus lobectomy in surgical treatment of elderly patients with early-stage non-small cell lung cancer (STEPS): Study protocol for a randomized controlled trial. Trials 2016;17:191.

11. Cao C, Gupta S, Chandrakumar D, et al. Meta-analysis of intentional sublobar resections versus lobectomy for early stage non-small cell lung cancer. Ann Cardiothorac Surg 2014;3:134-41.

12. Schuchert MJ, Abbas G, Pennathur A, et al. Sublobar resection for early-stage lung cancer. Semin Thorac Cardiovasc Surg 2010;22:22-31.

13. Shirvani SM, Jiang J, Chang JY, et al. Lobectomy, sublobar resection, and stereotactic ablative radiotherapy for earlystage non-small cell lung cancers in the elderly. JAMA Surg 2014;149:1244-53.

14. Yoshikawa K, Tsubota N, Kodama K, et al. Prospective study of extended segmentectomy for small lung tumors: The final report. Ann Thorac Surg 2002;73:1055-8; discussion 1058-9.

15. Okada M, Mimae T, Tsutani Y, et al. Segmentectomy versus lobectomy for clinical stage IA lung adenocarcinoma. Ann Cardiothorac Surg 2014;3:153-9.

16. Landreneau RJ, Normolle DP, Christie NA, et al. Recurrence and survival outcomes after anatomic segmentectomy versus lobectomy for clinical stage I nonsmall-cell lung cancer: A propensity-matched analysis. J Clin Oncol 2014;32:2449-55.

17. Pennathur A, Abbas G, Christie N, et al. Video assisted thoracoscopic surgery and lobectomy, sublobar resection, radiofrequency ablation, and stereotactic radiosurgery: Advances and controversies in the management of early stage non-small cell lung cancer. Curr Opin Pulm Med 2007;13:267-70.

18. Wei B, Eldaif SM, Cerfolio RJ. Robotic lung resection for non-small cell lung cancer. Surg Oncol Clin N Am 2016;25:515-31.

19. Cheng AM, Wood DE. Minimally invasive resection 
of early lung cancers. Oncology (Williston Park) 2015;29:160-6.

20. Park BJ, Heerdt PM. Minimally invasive surgical techniques in the treatment of lung cancer. Minerva Chir 2009;64:573-88.

21. Sullivan R, Alatise OI, Anderson BO, et al. Global cancer surgery: Delivering safe, affordable, and timely cancer surgery. Lancet Oncol 2015;16:1193-224.

22. Whitson BA, Groth SS, Duval SJ, et al. Surgery for earlystage non-small cell lung cancer: A systematic review of the video-assisted thoracoscopic surgery versus thoracotomy approaches to lobectomy. Ann Thorac Surg 2008;86:200816; discussion 2016-8.

23. Park BJ, Melfi F, Mussi A, et al. Robotic lobectomy for non-small cell lung cancer (NSCLC): Longterm oncologic results. J Thorac Cardiovasc Surg 2012;143:383-9.

24. Melfi FM, Menconi GF, Mariani AM, et al. Early experience with robotic technology for thoracoscopic surgery. Eur J Cardiothorac Surg 2002;21:864-8.

25. Pardolesi A, Park B, Petrella F, et al. Robotic anatomic segmentectomy of the lung: technical aspects and initial results. Ann Thorac Surg 2012;94:929-34.

26. Toker A, Avalp K, Uytumaz E, et al. Robotic lung segmentectomy for malignant and benign lesions. J Thorac Dis 2014;6:937-42.

27. Veronesi G. Robotic lobectomy and segmentectomy for lung cancer: results and operating technique. J Thorac Dis
2015;7:S122-30.

28. Musgrove KA, Hayanga JA, Holmes SD et al. Robotic versus video assisted thoracoscopic surgery pulmonary segmentectomy: a cost analysis. Innovations 2018;13:338-43.

29. Liang H, Liang $W$, Zhao L, et al. Robotic versus videoassisted lobectomy/segmentectomy for lung cancer: A meta-analysis. Ann Surg 2018;268:254-9.

30. Wei B, D'Amico TA. Thoracoscopic versus robotic approaches: advantages and disadvantages. Thorac Surg Clin 2014;24:177-88.

31. Le Moal J, Peillon C, Dacher JN. Three-Dimensional computed tomography reconstruction for operative planning in robotic segmentectomy: a pilot study. J Thorac Dis 2018;10:196-201.

32. Shimizu K, Nakazawa S, Nagashima T, et al. 3D-CT anatomy for VATS segmentectomy. J Vis Surg 2017;3:88.

33. Kuo SW, Tseng YF, Dai KY, et al. Electromagnetic Navigation Bronchoscopy Localization for Lung Resection via Video-Assisted Thoracoscopic Surgery: A PropensityMatched Study. J Clin Med 2019;8:379.

34. Luo K, Lin Y, Lin X, et al. Localization of peripheral pulmonary lesions to aid surgical resection: a novel approach for electromagnetic navigation bronchoscopic dye marking. Eur J Cardiothorac Surg 2017;52:516-21.

35. Hyun K, Park IK, Song JW, et al. Electromagnetic navigation bronchoscopic dye marking for localization of small subsolid nodules: Retrospective observational study. Medicine (Baltimore) 2019;98:e14831.
Cite this article as: Musgrove KA, Spear CR, Abbas K, Harris BR, Abbas G. Robotic pulmonary segmentectomy. J Thorac Dis 2021;13(10):6179-6186. doi: 10.21037/jtd.2019.12.68 